\title{
APPLICATION OF AHP TO INVENTORY MANAGEMENT AND COMPARISON TO CROSS ANALYSIS
}

\author{
Domenico Falcone \\ Department of Mechanics, Structures, Environment and Territory \\ University of Cassino \\ Cassino, FR, ITALY \\ E-mail: falcone@unicas.it \\ Alessandro Silvestri* \\ Department of Mechanics, Structures, Environment and Territory \\ University of Cassino \\ Cassino, FR, ITALY \\ E-mail: silvestr@unicas.it \\ Antonio Forcina \\ Department of Mechanics, Structures, Environment and Territory \\ University of Cassino \\ Cassino, FR, ITALY \\ E-mail: a.forcina@unicas.it \\ Antonio Pacitto \\ Department of Mechanics, Structures, Environment and Territory \\ University of Cassino \\ Cassino, FR, ITALY \\ E-mail: a.pacitto@unicas.it
}

\begin{abstract}
The present work aims at choosing the most suitable model for materials management applied to the considered industrial system.

Initially, ABC Analyses were applied to materials management. In particular we have compared the management factors chosen in pairs through Cross Analysis. This procedure has led to the most appropriate management methodology, even if with some problems. In fact, $\mathrm{ABC}$ Analysis suggests different criteria of management for some products, depending on the pairs of factors used for the Cross Analysis.

To overcome this limitation, we suggested to use AHP Analysis, which allows you to simultaneously consider many criteria all at once for the optimal choice of materials management. In this way, the choice is univocal and is able to adopt the most appropriate technique. Moreover another advantage of AHP Analysis is the possibility of making a detailed analysis for each material, while ABC-Cross Analysis requires to split the stocks into classes, that have the same characteristics.
\end{abstract}

Keywords: AHP, ABC and Cross Analysis, Just In Time, MRP

${ }^{*}$ Corresponding author 


\section{Introduction}

The automotive sector is strategic in a global economy. It is a constantly evolving field, and the strong competition requires a continuous innovation. Dynamism and speed are two predominant aspects of that sector. A key ingredient for continuous improvement is the willingness to change and only through the critical observation of the present situation, after identifying possible areas of improvement, we can plan a change that will produce more efficiency. To be efficient means to achieve the desired results, using the best available resources.

The proposed work is based on a study for the optimization of materials management within a car company. The first part shows all the different methods of materials management. Subsequently, we described materials used in the department on which are carried out operations that bring added value to the product. In the second part of the paper, ABC Analysis has been applied in order to choose the right procedures for management materials. The choices made with this decision making support, were finally validated and compared with the results obtained by another analysis, AHP (Analytic Hierarchy Process).

\section{Methods of analysis}

In every industrial company, we need to obtain a correct logistic flow of materials, supported by a consistent flow of information. Generally, the production of goods or a service must be in accordance with customer requirements, both in the case of production on order and in the case of production for the warehouse. The main purpose of the planning process lies in the need of coordinating and harmonizing the demands of the market with the demands of the company, in terms of potential production system, and achieving the economic goals. The production programs should be based on the required quantity of product dispatched by the production department. Table 1 shows the main stages to achieve the desired objective. The steps listed in this table are in chronological order and each depends on the previous year.

\begin{tabular}{|c|c|c|}
\hline STATO & FASE & ATTIVITA' \\
\hline \multirow[t]{8}{*}{ PLANNING } & Demands planning & $\begin{array}{l}\text { Demand forecasting, order } \\
\text { management }\end{array}$ \\
\hline & $\begin{array}{l}\text { Aggregate Production Plan } \\
\text { (PP) }\end{array}$ & $\begin{array}{lll}\text { Planning commitments of } \\
\text { resources }\end{array}$ \\
\hline & $\begin{array}{l}\text { Resources } \\
\text { Planning (RRP) }\end{array}$ & $\begin{array}{l}\text { Check the availability of } \\
\text { resources }\end{array}$ \\
\hline & \multirow{2}{*}{$\begin{array}{ll}\begin{array}{l}\text { Master schedule } \\
\text { (MPS planned) }\end{array} & \text { planned } \\
\begin{array}{l}\text { Rough Cut } \\
\text { Planning (RCCP) }\end{array} & \text { Capacity } \\
\end{array}$} & $\begin{array}{l}\text { Tests for sequencing, } \\
\text { grading, subdivision }\end{array}$ \\
\hline & & Check load capacity \\
\hline & $\begin{array}{l}\text { Master schedule authorized } \\
\text { (MPS authorized) }\end{array}$ & $\begin{array}{l}\text { Actual sequencing, grading } \\
\text { and subdivision operations }\end{array}$ \\
\hline & $\begin{array}{l}\text { Materials Requirement } \\
\text { Planning (MRP) e Capacity } \\
\text { Requirement Planning (CRP) }\end{array}$ & $\begin{array}{l}\text { Explosion of materials } \\
\text { requirements and production } \\
\text { capacity requirements }\end{array}$ \\
\hline & $\begin{array}{lll}\begin{array}{l}\text { Operational plan } \\
\text { production }\end{array} & \text { for } \\
\end{array}$ & $\begin{array}{l}\text { Scheduling and association } \\
\text { priorities }\end{array}$ \\
\hline \multirow[t]{2}{*}{ PERFORMANCE } & $\begin{array}{l}\text { Release purchase orders for } \\
\text { materials and components }\end{array}$ & Supply of material \\
\hline & $\begin{array}{l}\text { Release order of production } \\
\text { and assembly }\end{array}$ & $\begin{array}{l}\text { Load machines and } \\
\text { departments }\end{array}$ \\
\hline CHECK & $\begin{array}{l}\text { Production control and } \\
\text { progress }\end{array}$ & $\begin{array}{l}\text { Feasibility Analysis, } \\
\text { bottlenecks, queues and } \\
\text { delays, reporting }\end{array}$ \\
\hline
\end{tabular}

Table 1 - Stages of planning and control 


\section{Materials}

In the department of the company studied, we can distinguish three different types of materials, classified according to their function:

- Row Material. They are materials whose function is the realization of the finished product. This category includes all the materials listed in the bill of materials of the products.

- Packaging. They are materials whose function is to package the finished product. Among these materials, there are the accessories used to ensure the integrity of the finished product during any handling and transportation activity.

- Consumables. They are materials whose function is not directly linked to the realization of the product, but they are helpful.

The number of packaging materials is far lower than the materials needed to achieve the final product (and therefore easier to control); therefore we focused only on the last ones (58 part codes).

\section{Application of $\mathrm{ABC}$ Analysis}

The method chosen for the study of materials is ABC Analysis. This statistical analysis is widely used in business, particularly for the management of materials. It provides a subdivision of the products concerned into three categories (A, B and C), defining which are the critical components on which to focus the attention. The $\mathrm{ABC}$ analysis can be carried out considering various factors of analysis, linked to the objective of the analysis itself and to the type of products in question. In the case study, we have analyzed only raw materials, for which we have considered the value of stock in the warehouse (it provides information about which materials have a higher value and thus higher capital amounts), the frequency of use (defined as the ratio between the number of versions and models on which the material is used), the material deterioration (defined as loss of function in a specified time period) and the risk of damage. For example, the paragraph 4.1 shows the way in which the analysis was performed on the value of stock.

\subsection{ABC analysis on the value of stock}

To conduct the $\mathrm{ABC}$ analysis on the value of stock in the warehouse was necessary to collect many historical data, starting from the documents of the suppliers. For every unit of material has been calculated its value by multiplying the relative standard cost and the quantity available in the warehouse. The computations were made based on the estimated volume of production in the current year. The result of $\mathrm{ABC}$ Analysis shows the materials that required more capital immobilization. The standard $\mathrm{ABC}$ analysis associates to Class A all materials whose percentage reaches $80 \%$, to Class B materials with a percentage ranging from $80 \%$ to $90 \%$ and to Class C the remaining materials. Instead we have chosen a different approach, in fact we have calculated the average value of stock in warehouse to define classes. In particular, we calculated the mean value of the stock by dividing the total value of stock and the total number of materials. Then, we have associated to Class A all materials with a value grater than the average, obtaining 13 materials. In the same way we have calculated a new average value for the remaining materials, obtaining Class B (higher values, 12 materials) and Class C (lower values, 33 materials).

\subsection{Cross analysis and choice of methods for materials management}

At this point, the approach followed required the application of Cross Analysis, which is a matrix that combines the results from the previous $\mathrm{ABC}$ analyses. In reality, previously we considered four criteria (value, frequency, deterioration, damage), therefore six Cross Analysis are necessary, considering the above criteria in pairs. At the end of this analysis it was possible to choose the method for materials management most appropriate to ensure the availability of raw materials when it is necessary to reduce stock costs and avoid break of stock and to ensure a certain level of customer service. As an example, Table 2 shows the Cross analysis in the case of frequency and stock value. Furthermore, it indicates the most suitable material management, the suggested time of verify and safety stock. 


\begin{tabular}{|c|c|c|c|c|c|}
\hline & & & \multicolumn{3}{|c|}{ STOCK VALUE } \\
\hline & & & $\mathbf{A}$ & B & $\mathbf{C}$ \\
\hline \multirow{9}{*}{$\begin{array}{l}\mathbf{F} \\
\mathbf{R} \\
\mathbf{E} \\
\mathbf{Q} \\
\mathbf{U} \\
\mathbf{E} \\
\mathbf{N} \\
\mathbf{C} \\
\mathbf{Y}\end{array}$} & \multirow{3}{*}{$\mathbf{A}$} & MANAGEMENT & JIT/MRP(requirements) & $\begin{array}{c}\text { MRP/BALANCING } \\
\text { COSTS/MIN COST } \\
\text { UNIT } \\
\end{array}$ & $\begin{array}{c}\text { MRP(fixed } \\
\text { quantity) }\end{array}$ \\
\hline & & VERIFY & PICKING & PICKING & MONTHLY \\
\hline & & SAFETY STOCK & MINIMUM & MINIMUM & STOCK \\
\hline & \multirow{3}{*}{ B } & MANAGEMENT & JIT/MRP(requirements) & $\begin{array}{c}\text { MRP/BALANCING } \\
\text { COSTS/MIN COST } \\
\text { UNIT }\end{array}$ & $\begin{array}{c}\text { MRP(fixed } \\
\text { quantity) }\end{array}$ \\
\hline & & VERIFY & PICKING & EVERY 15 DAYS & MONTHLY \\
\hline & & SAFETY STOCK & MINIMUM & MINIMUM & STOCK \\
\hline & \multirow{3}{*}{ C } & MANAGEMENT & JIT/MRP(requirements) & $\begin{array}{c}\text { MRP/BALANCING } \\
\text { COSTS/MIN COST } \\
\text { UNIT }\end{array}$ & $\begin{array}{c}\text { MRP(fixed } \\
\text { quantity) }\end{array}$ \\
\hline & & VERIFY & PICKING & EVERY 15 DAYS & MONTHLY \\
\hline & & SAFETY STOCK & MINIMUM & MINIMUM & STOCK \\
\hline
\end{tabular}

Table 2 - Cross Analysis stock value/frequency and method of management suggested

The analysis suggests in the case of row materials the adoption of JIT (Just In Time) and MRP (requirements) (Material Requirement Planning), with some differences. In particular, for materials with the highest stock values (classes AA, AB, AC) we suggested JIT, thanks to the collaborative nature of the relationships that exist between the company (customer) and suppliers. For all other materials MRP is proposed. For the materials of the classes BA, BB and BC, there are two similar methods, the balancing of costs or the minimum cost per unit. These two methods allow to calculate the economic order batch for which the total cost of storage is the same as the cost of launching in the first case, and a batch that present the minimum unit cost (considering both costs of launching and storage costs) in the case of the application of minimum cost per unit. In addition, for the materials with low values (Classes CA, CB, CC) we proposed a possible MRP management (fixed quantity), with a fixed quantity of the batch ordered, according to historical data. We suggested always a minimum stock. Only in the case of CA, CB, CB materials, we suggested a higher value of safety stock.

These kinds of considerations were made for all six Cross Analyses carried out, and we arrived to different conclusions for materials management, depending on the pair of factors taken into account.

In particular, Cross Analysis, considering as criteria for assessing the value of stock and the frequency of use, places the component "seal" into the AC class, it has a high value (calculated as the product of the amount used in the different models of products developed and its cost per unit) and a low frequency of use. For this class of materials, JIT is proposed. Instead, considering a further Cross Analysis using criteria such as the risk of damage and deterioration, the component falls in the CC class, in fact it has a risk of damage and deterioration of little importance. In this second case, MRP (fixed amount) is suggested. It is clear that changing evaluation criteria, different responses are carried out. For this reason, it was necessary to adopt a different approach able to consider different criteria all at once.

\section{Comparison with AHP Analysis}

To overcome the limitations of Cross Analysis, you can use AHP Analysis, which allows considering many factors all at once for decision making. The first step is the problem identification, analyzing the materials and methods of management in order to realize a more efficient system. The second phase 
includes the identification of the objective, that is the choice of the management method best suited. The third stage involves the determination of the alternatives and the criteria that can regulate the choice. The alternatives are basically the choices available and in our case correspond to the procedures of management, in particular, JIT, MRP (requirements), MRP / Balance Cost / Minimum cost per unit, MRP (fixed amount). The criteria are the same of ABC Analysis. The objective is to identify a single method of managing for each component. Figure 1 shows the dominance hierarchy for the case examined, using the software Super Decisions.

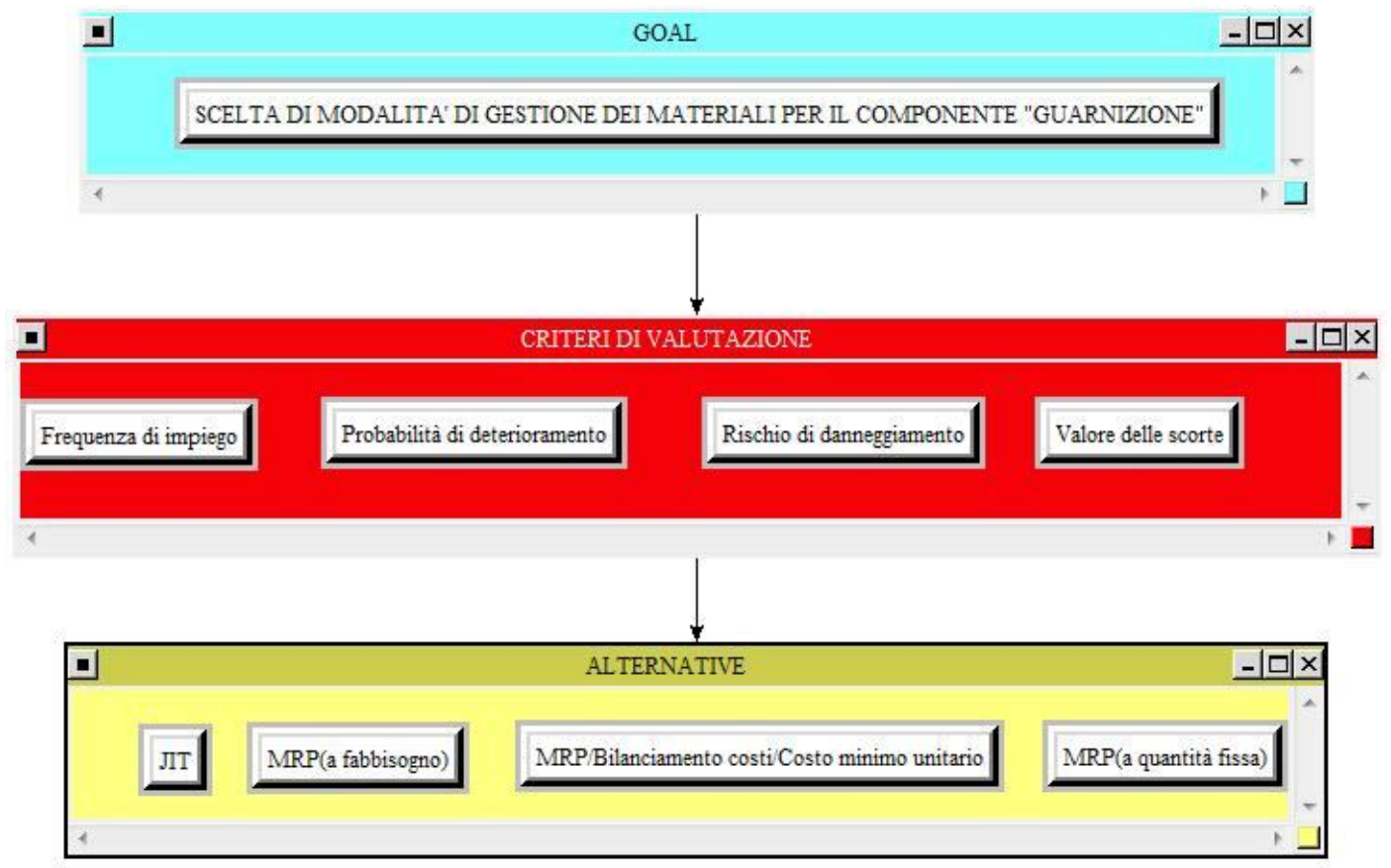

Figure 1- Dominance hierarchy for the case examined.

We used the method of comparison in pairs of all elements of the hierarchical structure. This method performs a comparison of the elements belonging to the lower level, with reference to the element at the upper one. In particular, the criteria are compared to each other to the overall objective, according to a scale of importance, giving priority to the alternative most influent. To assign different ratings scale is used the semantics of Saaty.

By applying this methodology is given a series of comparison matrices. In the figure n. 2, there is an example of application in the case of the component "seal".

\begin{tabular}{|l|l|l|l||c|}
\hline \multicolumn{1}{|c|}{ Name } & Graphic & Ideals & Normals & Raw \\
\hline \hline \multicolumn{1}{|c|}{ JIT } & & 1.000000 & 0.381849 & 0.190924 \\
\hline \hline MRP(a fabbisogno) & & 0.724231 & 0.276547 & 0.138273 \\
\hline \hline MRP(a quantità fissa) & & 0.365516 & 0.139572 & 0.069786 \\
\hline $\begin{array}{l}\text { MRP/Bilanciamento costi/ } \\
\text { Costo minimo unitario }\end{array}$ & & 0.529091 & 0.202033 & 0.101016 \\
\hline
\end{tabular}

Figure 2- AHP Results for the component "seal"

As you can see, the optimal choice is Just In Time for the management of component "seal". 


\section{Conclusions}

ABC-Cross Analysis suggests different materials management methods, depending on the particular criteria considered. In many case, it is a big problem for the analyst. To overcome this limitation, we used the AHP analysis, which allows you to simultaneously consider all the assessment criteria for the optimal choice of materials management. In this way, the choice is single and able to adopt the most appropriate technique of management. Another advantage of AHP, against ABC-Cross Analysis, is the possibility of carrying out the analysis for each material, while the ABC-Cross analysis requires to split the stocks into classes, each one related to a particular management method.

\section{REFERENCES}

John F., David M., Boodman. Programmazione della produzione e controllo delle scorte. Franco Angeli Editore.

A.Pareschi, A.Persona, E.Ferrari, A.Regattieri. Logistica integrata e flessibile per i sistemi produttivi dell' industria e del terziario. Editore: progetto Leonardo Bologna.

Giovanni Graziadei. Gestione della produzione industriale. Strumenti ed applicazioni per il miglioramento della performance. Editore Hoepli.

Domenico Falcone, Fabio De Felice, Thomas L. Saaty. Il decision making e i sistemi decisionali multi criterio. Le metodologie AHP e ANP. Editore Hoepli.

Fei, Giovannoni, Mocenni, Sparacino. Metodi di analisi multi criterio. Dipartimento di ingegneria dell'informazione, università degli studi di Siena.

Marco Cattaneo, Fabrizio Dallari. Rubrica logistica pratica. 